\title{
Unconformable stratigraphy in East Antarctica: Part I. Large firn cosets, recrystallized growth, and model evidence for intensified accumulation
}

\author{
Steven A. ARCONE, ${ }^{1}$ Robert JACOBEL, ${ }^{2}$ Gordon HAMILTON ${ }^{3}$ \\ ${ }^{1}$ US Army Engineer Research and Development Center, Cold Regions Research and Engineering Laboratory, \\ Hanover, NH, USA \\ E-mail: Steven.A.Arcone@usace.army.mil \\ ${ }^{2}$ Department of Physics, St Olaf College, Northfield, MN, USA \\ ${ }^{3}$ Climate Change Institute, University of Maine, Orono, ME, USA
}

\begin{abstract}
Unconformable firn stratigraphy exists throughout a $650 \mathrm{~km}$ long radar profile that we recorded down-flow of megadune fields in the Byrd Glacier (East Antarctica) catchment. Profile segments reveal cosets of prograding bedding sequences up to $90 \mathrm{~m}$ thick and with lateral, along-crest dimensions up to tens of kilometers. We profiled them in oblique section and nearly parallel to the prevailing wind. The prograding snow accumulates on broad, low windward slopes located above icebed depressions, which implies long-term slope stability. The apparent subglacial control implies that the accumulation progrades in balance with ice velocity, which we measured at $\sim 30 \mathrm{ma}^{-1}$. The sequences prograde over intensely modified and recrystallized wind-glaze firn, visible in the profiles as unstratified layers and zones up to several tens of meters thick. The intense recrystallization eliminates density stratification, and the altered layers appear to thicken into a connected network. Modeling of coset formation using wind and ice flow reproduces their dimensions and morphology. However, accumulation rates well above current regional estimates and existing data for megadunes are required because of the measured ice speed and required slope stability. The consistent unconformable strata along our traverse show that coset and recrystallized morphology extend far beyond the megadune fields.
\end{abstract}

\section{INTRODUCTION}

Megadune fields cover an estimated $500000 \mathrm{~km}^{2}$ of East Antarctica (Bohlander and Scambos, 2005). The megadunes are low-amplitude trains of dunes with ridge crests up to $100 \mathrm{~km}$ long and are distinguished from other types of dune by their distinctive dune and wind-glaze pattern. These trains are recognized in RADARSAT imagery (Fig. 1) by their dark windward slopes and light wind-glazed leeward slopes (Fahnestock and others, 2000). Beneath the megadunes, unconformable firn stratigraphy results from the accumulation hiatuses on the leeward slopes, while snow accumulates on the windward slopes and causes them to prograde directly or obliquely upwind (Frezzotti and others, 2002). Figure 1 also shows large and irregularly shaped nondunal accumulation areas within or peripheral to the dune fields (dark areas along and adjacent to the traverse in this image). In this paper, we show that these peripheral areas are also underlain by unconformable firn stratigraphy, though with feature dimensions on a much larger scale than beneath megadunes, and explore their causes. In Arcone and others (2012; henceforth Part II) we look at the deeper, englacial consequences of this stratigraphy.

Megadunes have amplitudes of 2-8 m, wavelengths of $2-5 \mathrm{~km}$ and slopes on the order of $1^{\circ}$ (Swithinbank, 1988; Fahnestock and others, 2000; Frezzotti and others, 2002, 2005). Snow accumulates exclusively on the windward slopes, making these 'antidunal' forms (Prothero and Schwab, 1996). Ground-penetrating radar (GPR) profiles obtained at the red asterisk location in Figure 1 (Bauer and others, 2004; Fahnestock and others, 2004; Scambos and others, 2004) and other megadune sites show a regular pattern of oblique or sigmoidal bedding sequences beneath the dunes and known as cosets (Miall, 1996). These cosets are separated by their own upper borders of intensely modified and recrystallized beds (Fig. 2a; Frezzotti and others, 2002, 2005) that appear unstratified. Consequently, the contact between a bed sequence and the adjacent modified layer below is an unconformity. The windward slopes are 1-2 km long, and the cosets are about 7-12 m thick and up to $\sim 10 \mathrm{~km}$ long. Cosets prograde directly or obliquely toward the wind (Frezzotti and others, 2002). As they travel down-ice and beneath the leeward slopes, the modified layers grow to a few meters thick with burial.

Here we discuss the formation of far larger and more irregular firn cosets that we profiled with $200 \mathrm{MHz}$ GPR along the 2006-07 US-ITASE (United States International Trans-Antarctic Scientific Expedition; Mayewski, 2003) traverse (Fig. 1). The similarity of the morphology of these larger, irregular firn cosets (Arcone and Jacobel, 2008) to megadune cosets shows that they formed from the same antidunal accumulation and recrystallization processes. In contrast, however, they have much larger accumulation slopes (recognizable in satellite imagery; Fig. 1); variable misalignment between ice, windward slope and wind directions; greater thicknesses; evidence of extensive glaze; and evidence that the recrystallization layer grows after burial (see Fig. 4 further below). These marked differences motivated us to explore the origin of this morphology.

Leeward slopes cover more than half a megadune field (Fahnestock and others, 2000; Bauer and others, 2004) and appear to have zero net accumulation. Regional accumulation rates in the Byrd Glacier catchment are typically 


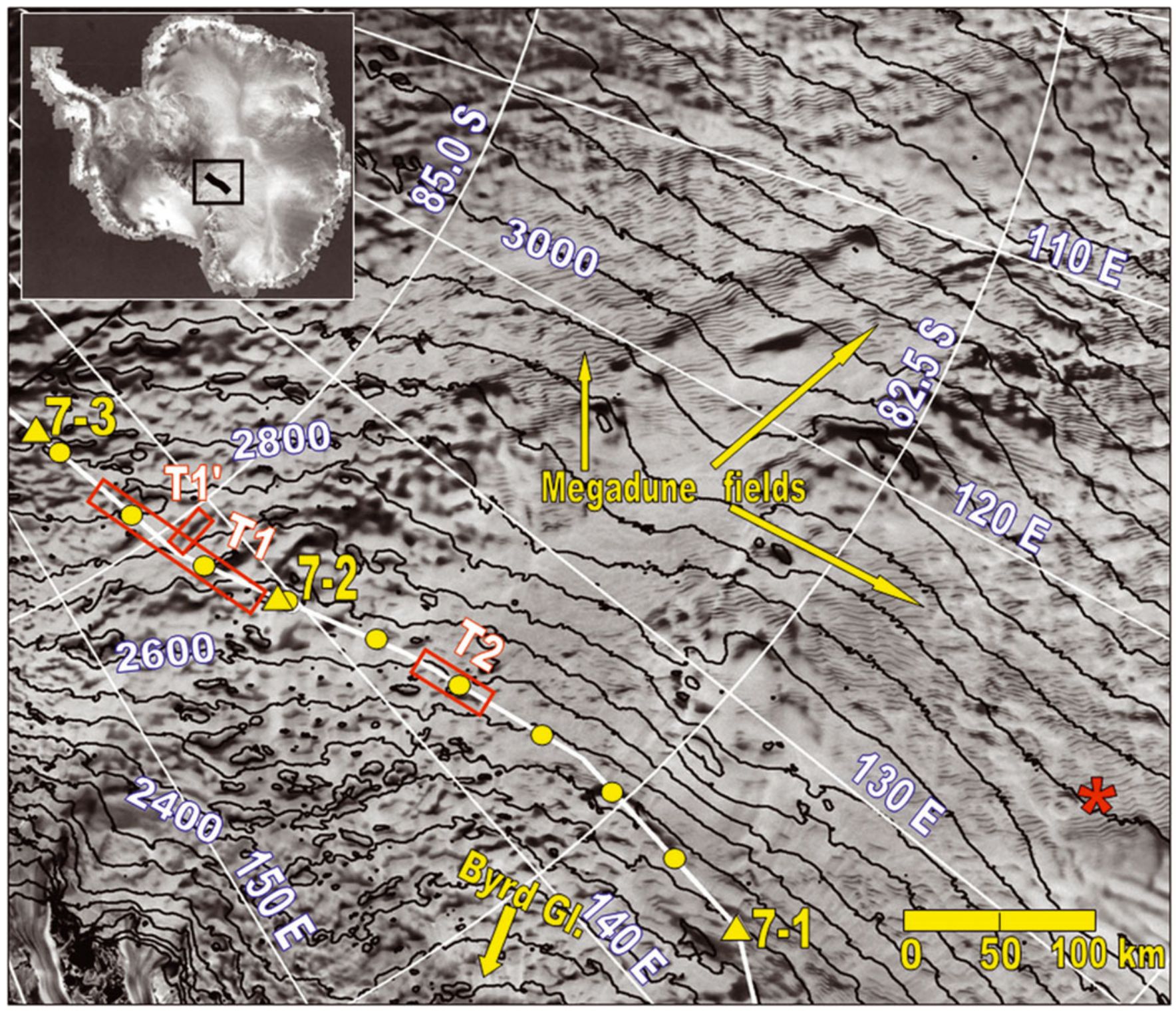

Fig. 1. The 1997 RADARSAT (Liu and others, 2001) image of East Antarctica, with the 2007 ITASE II traverse superimposed. Megadunes within the dune fields appear as alternating dark (windward accumulation slopes) and light (glazed leeward slopes) stripes. No megadune fields exist within $100 \mathrm{~km}$ of our traverse. Instead, irregular and large dark accumulation areas are dispersed along our traverse, and throughout and peripheral to the megadune fields. Yellow circles are $50 \mathrm{~km}$ apart. Elevation contours are in $50 \mathrm{~m}$ increments. Yellow triangles mark the distance reference stations, 7-1, 7-2 and 7-3, where we obtained ice velocities and density profiles. Profiles recorded along segments $\mathrm{T} 1, \mathrm{~T}^{\prime}{ }^{\prime}$ and $\mathrm{T} 2$ are discussed here; those along $\mathrm{T} 2$ and other segments are discussed in Part II. The red asterisk locates accumulation measurements and other GPR profiles cited in the text.

0.02-0.05 m w.e. $\mathrm{a}^{-1}$, from estimates of surface mass balance obtained by both observation and modeling (Arthern and others, 2006; Van de Berg and others, 2006). In megadune areas Frezzotti and others (2002), Courville and others (2007) and T. Scambos (personal communication, 2011) measured accumulation rates of $0.02-0.07 \mathrm{~m}$ w.e. $\mathrm{a}^{-1}$, with accumulation on dune crests appearing in GPR profiles as a large fraction of the maximum accumulation rate. Indirect evidence that higher accumulation rates may exist along our traverse comes from segments of the US-ITASE deepsounding radar profile (Jacobel and others, 2008; Welch and others, 2009) which reveal large subglacial depressions beneath areas with windward accumulation slopes (see below). This correspondence suggests that these slopes are stable (Budd and Carter, 1971). To keep the windward slopes in place, snow progradation needs to balance the ice speed of $30 \mathrm{~m} \mathrm{a}^{-1}$ we measured near these sections.
This evidence of surface slope stability, and transferring the megadune accumulation model to our traverse route, where ice speeds are substantially higher, led us to speculate that progradation rates (and thus accumulation) must be higher than in megadune areas. Consequently, our main objective is to estimate the accumulation rates that produce the morphology and dimensions of the cosets we profiled at $200 \mathrm{MHz}$. We first describe the coset bedding and recrystallization morphology, and the correspondence between the surface topography and the subglacial topography we recorded with deeper-penetrating $3.2 \mathrm{MHz}$ GPR. We then analyze our cosets with two-dimensional (2-D) models based on superposed accumulation layers separated in time, and discuss the accumulation rates we find that reproduce coset morphology and thicknesses.

Previous work on the origin of polar firn stratigraphy also focused on accumulation and recrystallization processes to 


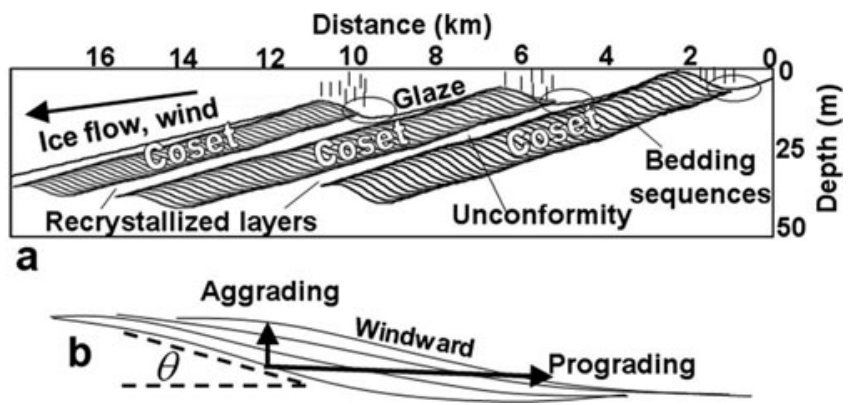

Fig. 2. (a) Diagrammatic axial section of cosets recorded beneath a megadune-type ripple train, and (b) depiction of accumulation on the small slopes $\left(\theta\right.$ is on the order of $\left.1^{\circ}\right)$, the right side of which exists within the ovals in (a). Dune strike is generally into the page for both (a) and (b). Snow accumulates on the windward faces, and glaze forms on the leeward faces. The intermediate layers are recrystallized upper parts of the coset beds, the surface of which represents an unconformity. In (b) the prograding rate is much greater than the aggrading rate.

explain long-distance conformable radar horizons in West Antarctica (Arcone and others, 2004, 2005a,b; Spikes and others, 2004). The horizons form from millimeter-thick depth-hoar layers of recrystallized snow and firn. The layers are caused by episodes of solar penetration that produce large near-surface temperature gradients that drive mass transport mainly toward the colder surface. Layer growth is limited by thin and relatively impermeable crusts, formed by wind and refrozen vapor. This finding is consistent with the firn stratification model of Alley (1988). In the Byrd catchment, thermal cracking, observed to at least $23 \mathrm{~m}$ depth beneath a glazed leeward slope (Severinghaus and others, 2010), provides likely subaerial and wind-pumped pathways to enhance the growth of the recrystallized modification of deep firn stratification that we find. We suggest that such pathways may be aided by the recrystallized layers themselves, and present an extra, unusual example in the Appendix. The subsequent deep burial of these layers is intrinsic to the englacial stratigraphy discussed in Part II.

\section{STUDY SITE}

Figure 1 shows a section of our 2007 traverse, which includes three coring and GPS velocity sites, marked 7-1, 7-2 and 7-3. The traverse is near, or intersects, few visible megadune features in this segment. Our field notes show that we constantly encountered low-lying and sparse sastrugi, firn cracks and $1 \mathrm{~m}$ high mounds of hoar frost overlying intersections of these cracks. A large megadune field described in previous remote-sensing and field studies (Fahnestock and others, 2000; Courville and others, 2007) is located $200 \mathrm{~km}$ northwest of site $7-1$. We discuss the accumulation patterns along our study in detail below. Our radar profiles consistently show unconformable firn and englacial strata for the next $650 \mathrm{~km}$ southward from site 7-1. Following that, firn and englacial strata became consistently conformable after $750 \mathrm{~km}$ from 7-1. Our selected profile segments $\mathrm{T} 1, \mathrm{~T} 1^{\prime}$ and $\mathrm{T} 2$ lie between sites 7-1 and 7-3, a distance of $473 \mathrm{~km}$, and illustrate the layering structures seen throughout this region. Cores obtained at our sites are extensively recrystallized and so could not be dated.
Elevation increases from $2454 \mathrm{~m}$ at 7-1, to $2645 \mathrm{~m}$ at 7-2, and to $2818 \mathrm{~m}$ at 7-3. The corresponding ice thicknesses we profiled are $\sim 2310 \mathrm{~m}$, slightly greater than $3310 \mathrm{~m}$ (an unusual depression), and $2410 \mathrm{~m}$, respectively. The general downhill slope is about $-0.04^{\circ}$ along segments $\mathrm{T} 1$ to within $120 \mathrm{~km}$ of $7-1$. At least the first $320 \mathrm{~km}$ south of 7-1 are within the Byrd Glacier catchment (Stearns, 2007). Average temperature at $10 \mathrm{~m}$ depth is likely -45 to $-50^{\circ} \mathrm{C}$ (Dixon, 2008). The likely gradient is $<0.03^{\circ} \mathrm{C} \mathrm{m}^{-1}$ to $130 \mathrm{~m}$ depth, as measured $500 \mathrm{~km}$ to the north at Taylor Dome (personal communication from G. Clow, 2009). Estimated accumulation rates for the catchment range from $0.02 \mathrm{~m}$ w.e. $\mathrm{a}^{-1}$ (based on the $23 \mathrm{~km}^{3} \mathrm{a}^{-1}$ ice flux through Byrd Glacier; Stearns, 2007) to $0.05 \mathrm{~m}$ w.e. $\mathrm{a}^{-1}$ (based on modeling, and surface and satellite observations; Giovinetto, 1963; Vaughan and others, 1999; Arthern and others, 2006; Van der Berg and others, 2006).

We measured ice velocities of $86.71 \mathrm{~m} \mathrm{a}^{-1}$ (at $106^{\circ}$ east of north), $30.09 \mathrm{~m} \mathrm{a}^{-1}$ (at 58 ) and $41.47 \mathrm{~m} \mathrm{a}^{-1}$ (at $43^{\circ}$ ) at sites 7-1, 7-2 and 7-3, respectively. Velocity errors are given below. These directions are generally orthogonal to the traverse. The speed at 7-2 is consistent with the 35$50 \mathrm{~m} \mathrm{a}^{-1}$ balance velocities mapped just $20 \mathrm{~km}$ north (Bamber and others, 2009), reflects streaming and accelerating towards the Byrd Glacier trunk (Liu and others, 1999; Part II) and strongly contrasts with the generally $5 \mathrm{~m} \mathrm{a}^{-1}$ or lower speeds throughout the up-ice flow dune fields (Bamber and others, 2009). The ice speed at the megadune site in Figure 1 is $4.3 \mathrm{~m} \mathrm{a}^{-1}$ (personal communication from T. Scambos, 2011). The local average surface katabatic wind directions we use in our model are based on previous atmospheric modeling (Parish and Bromwich, 1987; Parish, 1988) and are shown by Siegert and others (2003). The modeled wind direction is generally south to north and parallel to our traverse from 7-2 to 7-3. Within the Byrd catchment after $300 \mathrm{~km}$ north of site $7-1$, the wind turns towards the Ross Ice Shelf and is nearly parallel to ice flow.

\section{METHODS}

\subsection{Radar}

We used a GSSI (Geophysical Survey Systems Inc., Salem, NH) System10B control unit and GSSI Model 5106 '200 MHz' bistatic antenna unit, within which the antennas are shielded to reduce clutter. Arcone and others (2004, $2005 a, b)$ describe our radar system and processing, but with a unit having $400 \mathrm{MHz}$ antennas. The '200 MHz' antenna unit radiates the same pulse waveform, the spectral center frequency of which was close to $200 \mathrm{MHz}$. We recorded 1024 16-bit samples per trace, with range gain. Each trace record spans $1000 \mathrm{~ns}$. Although this sampling rate produced only five samples per wave period ( $5 \mathrm{~ns}$ ), it still reproduced the received waveform and allowed us to record 24 traces $\mathrm{s}^{-1}$. The 32-fold stack we applied during recording and an additional, processed threefold stack provided one trace every $13.2 \mathrm{~m}$ at a traverse speed of $3.3 \mathrm{~m} \mathrm{~s}^{-1}$. Random noise suppression for the total, 96-fold stack is $20 \mathrm{~dB}$. We processed with automatic gain control to amplify all horizons nearly equally. Profile migration is unnecessary because the horizons are nearly flat relative to the surface.

Simultaneously, we recorded profiles of the englacial and subglacial regimes with $3.2 \mathrm{MHz}$ transient-type GPR, which 
we detail in Part II. The system used collinear dipoles dragged along the traverse and produced a pulse similar in form to that at $200 \mathrm{MHz}$. Post-processing included normal moveout correction and migration. We display only the subglacial sections of the migrated profiles here.

For the $200 \mathrm{MHz}$ radar data, we corrected all our profiles for elevation and equalized the number of traces per kilometer. We calibrated depth, $d$, using the simple equation

$$
d=c t / \sqrt{\varepsilon,}
$$

where $t$ is time in seconds, $c=3 \times 10^{8} \mathrm{~m} \mathrm{~s}^{-1}$ and $\varepsilon=2.7$ for firn and 3.15 for ice. At this firn value, the predominantly $1 \frac{1}{2}$-cycle pulse provided an interface resolution of $0.7 \mathrm{~m}$ and the $1000 \mathrm{~ns}$ trace duration gave $90 \mathrm{~m}$ depth. The firn value is based on a projected average density of $0.76 \mathrm{~kg} \mathrm{~m}^{-3}$ to $90 \mathrm{~m}$ depth for density profiles recorded in 40-50 deep cores obtained at sites 7-1, 7-2 and 7-3 (located in Fig. 1), and on the firn dielectric calibration of Kovacs and others (1996). Below $\sim 10 \mathrm{~m}$ depth, the density profiles vary up to $20 \mathrm{~kg} \mathrm{~m}^{-3}$ from a normal exponential-type trend with depth, most likely because of the recrystallized firn. Core breakage sometimes forced us to estimate core volume. We estimate that firn density reaches $900 \mathrm{~kg} \mathrm{~m}^{-3}$ at $\sim 80 \mathrm{~m}$ depth.

In using a constant $\varepsilon=2.7$, we estimate a depth error less than $12 \%$ at shallow depths $(20 \mathrm{~m})$, and less than $2.1 \%$ at $90 \mathrm{~m}$ based on how the density profiles deviate from this average. The reference for the depth scale of the $3.2 \mathrm{MHz}$ subglacial profiles is the surface, which varied sufficiently in elevation that the single, fixed depth scale shown in our figures, which are not topographically corrected, gives an absolute elevation accuracy of $\sim 50 \mathrm{~m}$. The accuracy in determining the depth of the leading edge of a horizon is $\sim 5 \mathrm{~m}$.

We display profiles in a grayscale amplitude format: white indicates positive signal strength, black indicates negative, and gray is near zero. Most $200 \mathrm{MHz}$ profiles were processed with a Hilbert magnitude transform, which captured pulse amplitude envelopes and increased horizon clarity. Signal amplitude is then represented with dark tones. All 3.2 MHz profiles are compiled traces of waveform amplitude.

\subsection{GPS}

We used differential kinematic GPS to determine our traverse position and elevation with an antenna mounted on the traverse vehicle that dragged our antennas. Our accuracy for the GPS antenna location is better than $0.2 \mathrm{~m}$ for elevation and better than $0.1 \mathrm{~m}$ for horizontal position, based on root-mean-square values. GPS antenna elevation is corrected for its height and distance from the GPR antennas. The midpoint between the two $3.2 \mathrm{MHz}$ antennas was $\sim 143.5 \mathrm{~m}$ behind the GPS antenna and $135 \mathrm{~m}$ behind the $200 \mathrm{MHz}$ antennas, which we corrected for in aligning profiles. We used the $5 \mathrm{~m}$ (elevation contours) $500 \mathrm{~m}$ (grid spacing) ICESat (Ice, Cloud and land Elevation Satellite) digital elevation model (DEM) (DiMarzio and others, 2007) to determine surface elevation at locations where we extended our modeling off our traverse.

We measured ice velocity by determining kinematic solutions to positions recorded at intervals of 4-20 hours of dual-frequency GPS data each day, with surveys at each site conducted at least 1 day apart. Position uncertainty is $8 \mathrm{~mm}$, which corresponds to an error in annually averaged speeds of about $\pm 5.9 \mathrm{ma}^{-1}$ and places the error percentage between $7 \%$ and $20 \%$ over the range of velocities (87$30 \mathrm{~m} \mathrm{a}^{-1}$, respectively) that we measured.

\subsection{Satellite imagery}

We used RADARSAT $(6 \mathrm{~cm}$ wavelength, $125 \mathrm{~m}$ pixel resolution) satellite-based images (Jezek, 2003) to provide the surficial context of the environment along-, and just up-ice of our traverse. RADARSAT images show megadunes, but best reveal the large accumulation features in dark tones. Relatively coarser crystalline grains beneath the glaze on leeward slopes strongly backscatter the RADARSAT signals to produce white tones, while the windward slopes appear dark because of smaller grain sizes that absorb radiation, in addition to any reflective losses. Langley and others (2007, 2009) found that RADARSAT signal frequencies penetrate as much as $10 \mathrm{~m}$, so that backscatter does not necessarily originate from the near surface. Consequently, near-surface recrystallization and even glaze may cover a slope that appears dark, which means that the scatter likely originates from underlying stratification.

We also used Moderate Resolution Imaging Spectroradiometer (MODIS) images $(620-876 \mathrm{~nm}$ wavelengths, $250 \mathrm{~m}$ resolution) to check for megadune features, but find little difference from the RADARSAT images for our areas. Optically, the glazed leeward slopes forward-scatter light away from the observation point (Sun behind the satellite) to produce relatively darker tones (Fahnestock and others, 2000) while the rougher windward slopes appear whiter because of stronger light backscatter.

\section{RESULTS AND DISCUSSION}

The coset profiles we discuss are located along T1 (Fig. 3), which is oriented mainly upslope from north to south. T1 is well aligned with the modeled wind direction and traverses several elongated accumulation features, indicated by dark areas in the RADARSAT image and labeled $\underline{\mathrm{a}}-\underline{\mathrm{d}}$ The major cosets we discuss, Cs1, Cs3 and Cs5, are located between these features. This image shows the nearest megadune fields to be $110 \mathrm{~km}$ west. Distances shown along T1 in Figure 3 are referred to in the radar profile figures that follow. T1 is highly oblique to ice flow. Profile $\mathrm{T}^{\prime}{ }^{\prime}$ was recorded along accumulation feature $\underline{c}$. The ice velocities of $30.09 \mathrm{ma}^{-1}$ at site 7-2 and $41.47 \mathrm{~m} \mathrm{a}^{-1}$ at site 7-3 suggest a characteristic speed between these sites so that ice movement was only $\sim 300 \mathrm{~m}$ in the 10 years between recording of the RADARSAT image and the radar profile.

Figures 4 and 5 illustrate the characteristics and hypothesized evolution of the major cosets and the modified firn layers associated with their leeward subaerial upper surfaces. The profiles in these figures overlap so that the full lengths of individual cosets are visible. The coset morphology suggests a number of processes at work, but the basic ones are windward slope progradation, slope control by subglacial relief, bedding progradation into the wind, modification of the beds by recrystallization, and their subsequent growth. Although T1 is nearly parallel to the wind, Figures 4 and 5 provide an oblique section of the cosets because of the ice flow direction.

\subsection{Coset origin: windward slopes and progradation}

Figures 4 and 5 illustrate the origin of bedding sequences of cosets on windward slopes. Clearly, Cs1-3 begin on 


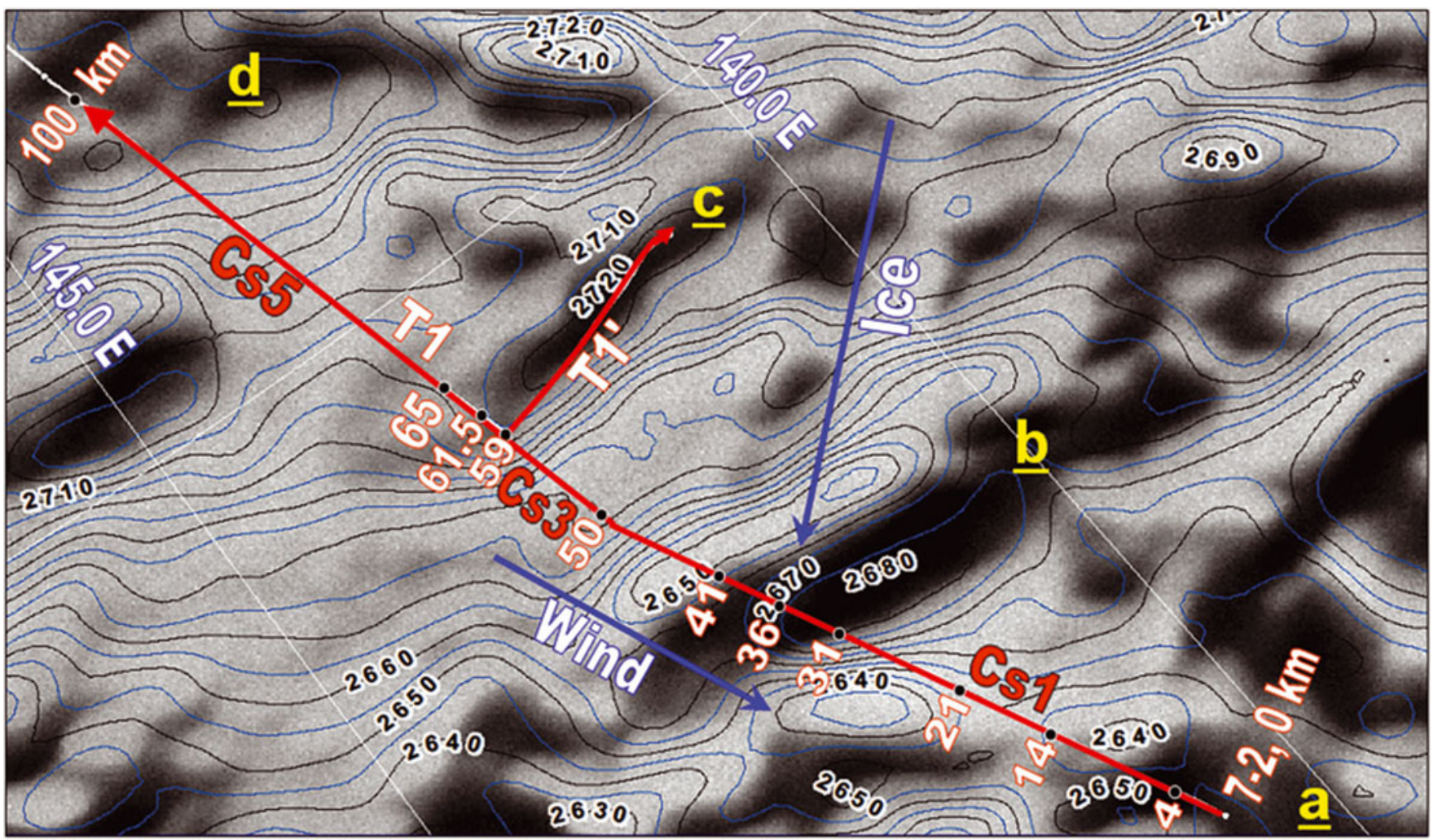

Fig. 3. (a) Transects $\mathrm{T} 1$ and $\mathrm{T} 11^{\prime}$ (red lines) superimposed on the RADARSAT image. We locate the larger cosets Cs1, Cs 3 and Cs5. Features $\underline{\mathrm{a}}-\underline{\mathrm{d}}$ are windward accumulation slopes located over ice-bed depressions. Elevation contours are in meters.

windward slopes, and so does Cs5 (not shown). The slopes appear within accumulation features $\underline{a}-\underline{d}$ in Figure 3 . The most prominent is windward slope $\underline{b}$ (Fig. 4), which loses $40 \mathrm{~m}$ in elevation from 30 to $41 \mathrm{~km}$ and is followed by a rising leeward slope. Its average slope of $+0.21^{\circ}$ is significantly larger than the general traverse slope of $-0.04^{\circ}$. In contrast, the generating slope of Cs3 (Fig. 5a) is only $0.07^{\circ}$, the elevation change is only $4 \mathrm{~m}$, and it is followed by an extended trough $4 \mathrm{~km}$ long.

The windward slopes associated with features $\underline{a}-\underline{d}$ are all situated over ice-bed depressions, and precede the downwind ice-bed rises by $2-3 \mathrm{~km}$. In Figure $4 \mathrm{a}$, windward slope b lies over a subglacial depression that spans $13 \mathrm{~km}$, and whose crest precedes that of a $420 \mathrm{~m}$ rise by $2 \mathrm{~km}$. The small windward slope a between 5 and $8 \mathrm{~km}$ precedes a depression too deep to be recorded continuously for the following $10 \mathrm{~km}$ to the north. The crest above the rise of windward slope $\underline{c}$ precedes a subglacial rise of $170 \mathrm{~m}$ (Fig. $5 \mathrm{~b}$ ) by $3 \mathrm{~km}$. This relief is preceded by an average elevation decrease of $<100 \mathrm{~m}$ from 60 to $67 \mathrm{~km}$. Not shown is the complete Cs5, which originates beneath feature $\mathrm{d}$ with a windward slope whose crest precedes that of a $200 \mathrm{~m}$ subglacial rise by $2 \mathrm{~km}$.

This correspondence between surface and ice-bed relief, the lag between crests, and the relatively higher ice speeds suggest basal slip and that our large accumulation slopes remain stationary (Budd and Carter, 1971). Consequently, as opposed to megadunes, which prograde into or oblique to the wind (Fahnestock and others, 2000; Frezzotti and others, 2002), it appears that the prograding accumulation of snow along the breadth of slopes $\underline{\mathrm{a}}-\underline{\mathrm{d}}$ must be balanced by ice speed.

\subsection{Coset bedding}

As with firn stratigraphy in West Antarctica (Arcone and others, 2004, 2005b), the stratification beneath windward slopes begins as layers of depth hoar, but likely centimeters rather than millimeters thick because of long-term growth under more extreme thermal gradients (Albert and others, 2004; Courville and others, 2007). The hoar is less dense than its surrounding firn.

The beds of Cs1 in Figure 4a formed along the entire $10.5 \mathrm{~km}$ length of the large windward slope. The increasing concavity within the sigmoidal shape of the beds beneath the slope (in the figure inset) shows that the beds thicken with depth, with heaviest accumulation near the slope center. The accumulation decreases toward a very low amount by the crest. In contrast, accumulation horizons along the windward slope of Cs3 in Figure 5 a extend along part of the crest above the slope (as also observed in megadunes) and then along the entire slope length. The slope and following trough extend $8 \mathrm{~km}$, where the traverse passed the edge of feature $\underline{c}$, from 59 to $64 \mathrm{~km}$.

Progressing northward from the slope, all beds have a simple or distorted sigmoidal shape, and appear to be about 8-10 km long in Cs1 and 2.5-4 km long in Cs3, or about the length of the accumulating slope in these oblique transects. They are longest just behind the windward slopes; farther north they recrystallized and lost length. The thickness of the visible Cs3 beds varies from 30-35 m near $59 \mathrm{~km}$, to $45 \mathrm{~m}$ at $47 \mathrm{~km}$. Including the recrystallized layer, we think that the thickness at $47 \mathrm{~km}$ may be $50 \mathrm{~m}$.

The length of Cs3 is at least $28 \mathrm{~km}$; at the north end it appears to continue below the profile depth. Along ice flow, Cs3 may extend at least $40 \mathrm{~km}$ from the western tip of feature 

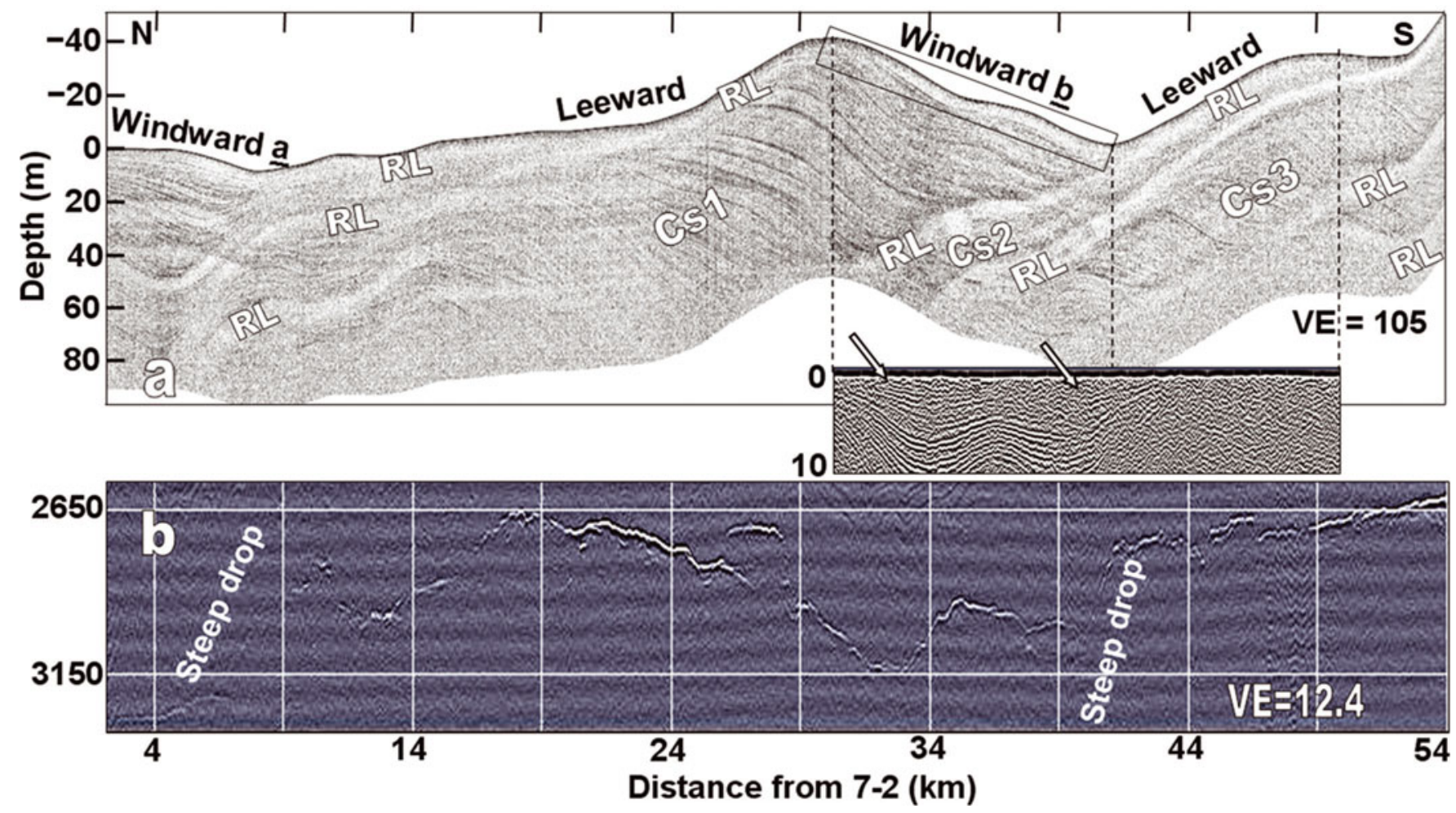

Fig. 4. (a) $200 \mathrm{MHz}$ profile of firn along $\mathrm{T} 1$ showing cosets $\mathrm{Cs} 1-3$ and modified layers RL; and (b) the corresponding $3.2 \mathrm{MHz}$ subglacial profile. The inset shows faint strata near the windward surface (arrows) and the increasing thickness of the beds along the slope, and no stratification beneath the leeward slope. The subglacial profile shows steep elevation drops beneath the windward slopes. From $30 \mathrm{~km}$ the relative horizon intensity across the entire section progressively weakens with distance north.

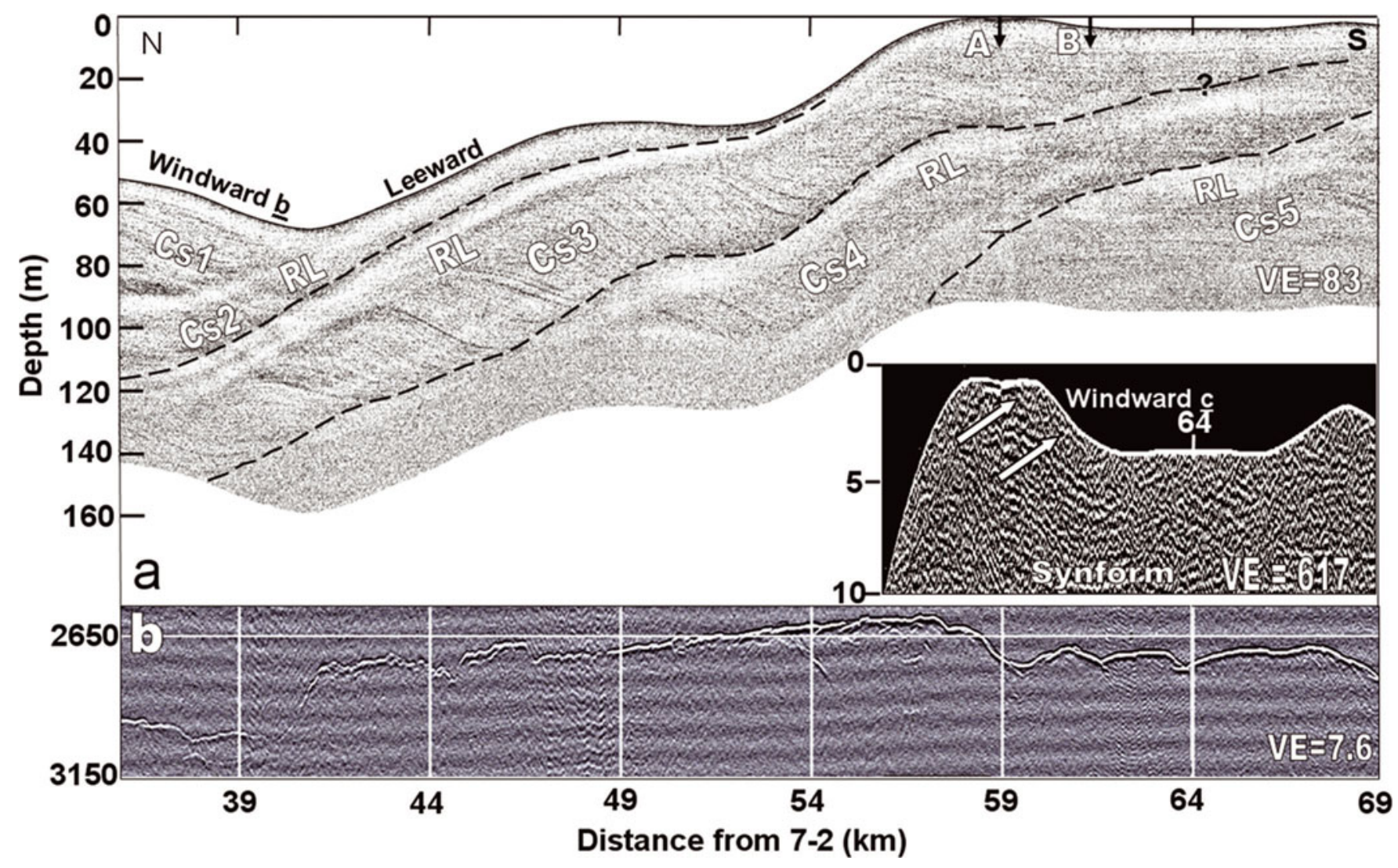

Fig. 5. (a) Continued $200 \mathrm{MHz}$ profile of $\mathrm{T} 1$ and (b) corresponding subglacial profile. The dashed lines in (a) outline cosets and include their upper recrystallized borders. The arrow labeled $\mathrm{A}$ is at the start of profile $\mathrm{T} 1^{\prime}$, and that labeled $\mathrm{B}$ is at the center of the windward slope at $61.5 \mathrm{~km}$. The detail in the inset in (a) shows near-surface strata (arrows) that begin $\sim 1 \mathrm{~km}$ from the crest edge, span the windward slope, and then disappear within the adjacent trough and leeward slope. In (c) the ice bed drops $170 \mathrm{~m}$ between 57 and $60 \mathrm{~km}$. 


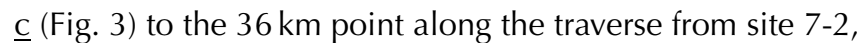
given that the formation uniformly progressed from all of feature $\underline{c}$. These two points give a $52^{\circ}$ direction east of north for the ice flow, only $6^{\circ}$ less than the direction we measured $40 \mathrm{~km}$ to the north at site 7-2. A distance-weighted interpolation between sites $7-2$ and $7-3$ gives $53^{\circ}$, so any error in ice-flow direction is not significant.

\subsection{Bedding modification: recrystallized and modified layers}

The modified and recrystallized layers reside beneath all leeward slopes and on the upper border of the cosets in Figures $4 \mathrm{a}$ and $5 \mathrm{a}$. Bedding fades into them, which shows these layers are part of their underlying cosets, but recrystallization has modified or destroyed their density stratification. A lack of near-surface stratification also appears on the windward slopes of Cs1 and Cs3 in Figures $4 \mathrm{a}$ and $5 \mathrm{a}$, respectively, but the detail shown in the insets reveals faint stratification, and none beneath the adjacent leeward slopes. Many of these layers thicken with depth and clearly reach beneath the $90 \mathrm{~m}$ that we profiled. Consequently, they grew after burial, and, as they thickened, they merged. It appears that so much growth and merging occurred at the north side of T1 in Figure 4a that the entire body of firn has been modified, thereby changing or erasing the density contrast that defined the original isochronal unconformity. No strata are visible along the entire base of both profiles. Ultimately, it appears that all these layers connect to a surface layer.

Altogether, it appears that $\sim 72 \%$ of the very near surface along the $164 \mathrm{~km}$ from 7-2 to 7-3 recrystallized, as determined by the lack of stratification within $5 \mathrm{~m}$ of the surface, such as in the inset of Figure $4 a$. The variable signal amplitudes from trace to trace make it impossible to use a more quantitative approach such as one based on a threshold value of signal amplitude. This is a unique part of the traverse because elevation constantly increased southward and the traverse headed into the wind. We estimate only $41 \%$ recrystallization for the traverse part that was not oriented into the wind from 7-1 to 7-2 and along which topography is fairly flat. We estimate $50 \%$ recrystallization for the first $134 \mathrm{~km}$ from $7-3$ to $7-4$, along which elevation increased over only a short section. In total, for $650 \mathrm{~km}$ from site $7-1 \sim 390 \mathrm{~km}$ of the near surface appears modified by recrystallization, or $60 \%$ of the traverse from site 7-1 before stratigraphy becomes continuously surfaceconformable. Either the overall linear value of $60 \%$ or the more reliable $72 \%$ between $7-2$ and $7-3$ is consistent with an estimate of $>50 \%$ wind-glazed leeward slopes throughout the megadune fields described above.

\section{MODELING}

We model Cs3 (Fig. 5) because of its well-defined morphology. However, our cross-sectional view of Cs3 is mostly aligned with wind, but not with the ice flow direction. Consequently, we first consider the effect of these different directions upon our 2-D profiled bed lengths and thicknesses with a simple three-dimensional (3-D) model. We then describe the results of a 2-D model based on the superposition of accumulation contours, with each representing an isochronous spatially constrained pulse of snow.

\subsection{Three-dimensional model and stretch factor}

Figure 6a shows our geometry. Our coordinate origin is at $61.5 \mathrm{~km}$ from site 7-2, which is where the initial accumulation horizons of Cs3 are centered (Fig. 5a). The $x$-axis is $52^{\circ}$ west of south and parallel to ice flow. The strike of feature $\underline{c}$ is $\sim 38^{\circ}$ off the $x$-axis, and the traverse is $\sim 74^{\circ}$ to the strike of feature $\underline{c}$. Feature $\underline{c}$ varies only $\pm 4 \mathrm{~m}$ in elevation from a mean of $2719 \mathrm{~m}$, and slopes to windward on the south side. Its bedding horizons (Fig. 6b) are 35$40 \mathrm{~m}$ thick and up to $19 \mathrm{~km}$ long, as expected along slope. Given that the part of $\mathrm{Cs} 3$ that we first crossed is generated at the western tip of feature c, Cs 3 is then $40 \mathrm{~km}$ long from this point to where it intersects our traverse at $36 \mathrm{~km}$ from site 7-2. At an interpolated speed of $32.5 \mathrm{~m} \mathrm{a}^{-1}$ it would have taken 1231 years for snow to reach our traverse along this line.

The important general feature of Figure $6 \mathrm{a}$ is that the ice, wind and strike of the windward slope are not aligned with each other. Cs3 appears as a dipping coset because we continually traversed a shallower part of the coset as we approached the slope. We first model Cs3 as a dipping sinusoidal surface with a $10 \mathrm{~km}$ wavelength and $40 \mathrm{~m}$ peakto-peak amplitude to find the percentage by which the sigmoidal bed horizons are apparently foreshortened by our traverse orientation. Figure $7 \mathrm{c}$ shows that the traverse orientation reduces the $10 \mathrm{~km}$ wavelength to $6.4 \mathrm{~km}$ but does not reduce amplitude. Assuming that all cross sections down-ice and parallel to feature $\underline{c}$ are similar, we then required our 2-D along-ice axial reconstruction to stretch any model of the recorded profile by a factor of 10/ $6.4=1.56$.

In the profile of Figure $5 \mathrm{a}$, the visible bedding lengths are $\sim 3 \mathrm{~km}$; including the upper recrystallized layer, they were originally $4-5 \mathrm{~km}$ long. Considering the stretch factor, the actual beds are likely $6-8 \mathrm{~km}$ along ice flow because that is the length of an oblique, along-ice section spanning feature $\underline{c}$ in Figure 7a. The 1.56 stretch factor is also consistent with our assumed coset direction being parallel to ice flow because the $25.5 \mathrm{~km}$ along-traverse distance from the windward center of generation at $61.5 \mathrm{~km}$ to the first detection at depth at $36 \mathrm{~km}$ scales to the along-ice flow length of $40 \mathrm{~km}$ by a factor of 1.57 . Consequently, in our following 2-D constructions we stretch the $28 \mathrm{~km}$ length of an along-wind model of $\mathrm{Cs} 3$, to an along-ice flow model of $44 \mathrm{~km}$.

\subsection{Two-dimensional formulation}

Our approach is similar to that of Arcone and others (2005b). We used a Gaussian pulse shape to simulate the synformal bed appearance in our profiles. We compute the accumulation depth, $z(x, t)$, at any distance, $x$, and time, $t$, by superposing successive, multi-year accumulations having peak amplitude $A_{n}$, each of which progressively moves down-ice at a yearly rate $v$. The value of $z$ is then

$$
z=z_{\mathrm{s}}+z_{\mathrm{b}}+\sum_{n} A_{n} \exp \left[-D\left(x-v t-x_{0}\right)^{2}\right],
$$

where $x$ may be along or oblique to the prograding direction, $x_{0}$ locates the peak value for the initial accumulation which we placed on the windward slope, $z_{\mathrm{s}}$ is the surface topography, $z_{\mathrm{b}}$ is the bedding depth relative to the surface, and $n$ is the number of superimposed accumulation distributions. We calculated $z(\mathrm{~m}), x(\mathrm{~km}), A(\mathrm{~m}), t$ (years) and $v\left(\mathrm{~m} \mathrm{a}^{-1}\right)$ in multi-year increments. 

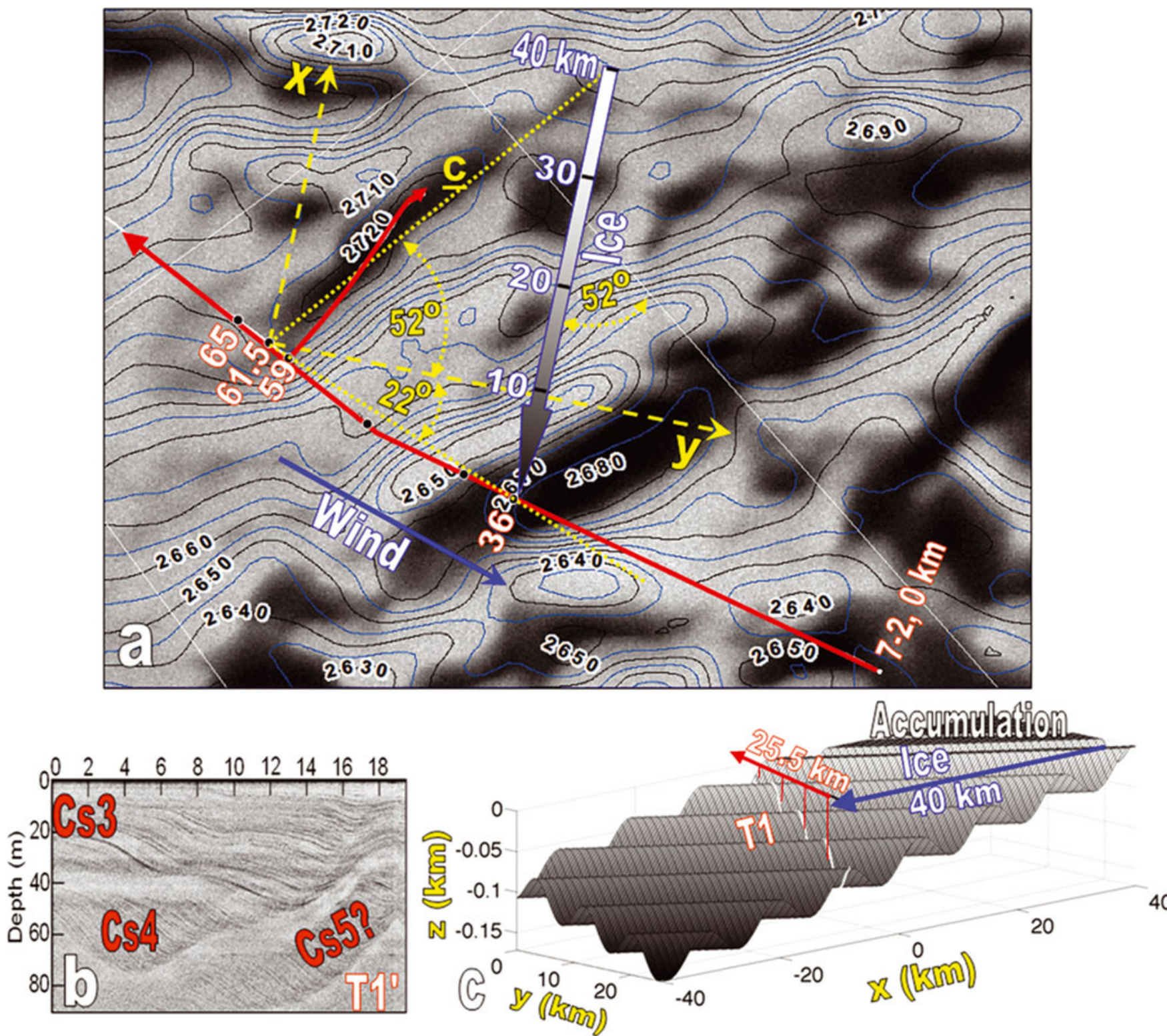

Fig. 6. (a) $x-y$ coordinate system we use to model Cs3; (b) firn profile along $\mathrm{T} 1^{\prime}$; and (c) simplified, 3-D sinusoidal model of Cs3 with traverse superimposed. The $x$-axis is parallel to interpreted ice flow, but in (c) it is displaced $25.5 \mathrm{~km}$ along the $y$-axis. The $y$-axis is $22^{\circ}$ from the wind direction. The darkening gradation within the arrow in (a) and that over the surface of (c) represent increasing coset depth.

The factor $x-v t$ displaces each contour down-ice at a distance $v t$ corresponding to the multi-year time increment, $t$, that each contour represents. This factor was also used by Black and Budd (1964) and Whillans (1975) to estimate the speed at which a sinusoidal accumulation distribution progrades. We fix $v t=0.5 \mathrm{~km}$, which supplies a sufficient density of contours to reach an asymptotic value of maximum bed thickness. At an interpolated ice flow speed of $32.5 \mathrm{~m} \mathrm{a}^{-1}$, each contour would represent 15.4 years, and we used enough contours to represent $>1200$ years. If contour density is chosen too low then greater displacement between accumulation peaks results and the effect of superposition is not realized. In this case, the modeled bed thickness would be uneven and an increased value of $A$ would be needed to provide a similar maximum value. After superposition the sigmoidal bed shapes farther down-ice are similar to a half-Gaussian form, as our profiles reveal. Along any isolated half-Gaussian slope, the average accumulation amplitude is $0.5 \mathrm{~A}$.
The exponential factor, $D$, determines the width of the Gaussian form, with smaller values giving wider distributions. Consequently, $D$ also affects how the beds will superimpose, and hence affects coset thickness in the vertical plane, as made evident by the vertical exaggeration in our profile displays. The quantity $D$ does not, of course, affect bed thickness when measured orthogonal to bed dip. We first adjusted $D$ to achieve desired bed length, and then varied $A_{n}$ to achieve desired layer thicknesses.

\subsection{Two-dimensional model: genesis of Cs3 and Cs1}

Given the correspondence between surface slope and subglacial elevation, we assume that accumulation persists on the long-term, spatially stable windward slopes despite high ice speeds. This means that the rate of prograding accumulation balances the high ice speed (Fig. 2b). Under the constraint of feature stability we intend our 2-D model to first replicate the radar profile in Figure $5 \mathrm{a}$ and then depict how this profile would appear in the direction along ice 


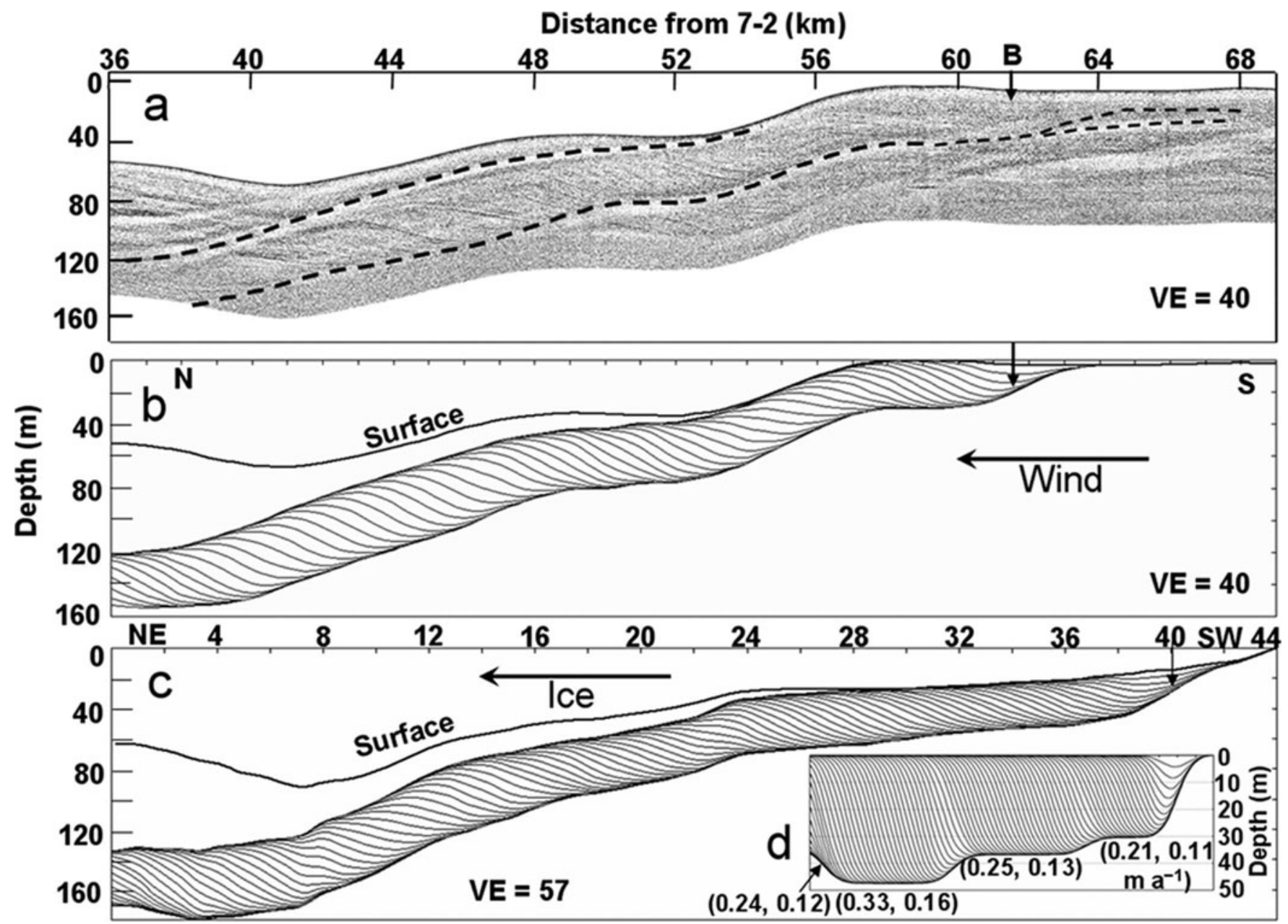

Fig. 7. (a) Cs3; (b) model of Cs3 along the traverse; (c) reconstructed model of Cs3 as it might appear along ice flow; and (d) the model without topographic correction, with peak and average accumulation rates (w.e.), respectively, labeled for each section. Each contour in (c) represents 15.4 years of deposition, and the profile is extended to $44 \mathrm{~km}$ to cover the width of RADARSAT feature $\underline{\mathrm{c}}$ in Figure 6a. All profiles begin at the $36 \mathrm{~km}$ distance from site 7-2, where surface elevation is referenced. The vertical arrows indicate the center of initial deposition. The greater vertical exaggeration in (c) precludes direct comparison with (b).

flow. The required parameters then show how the modeled cosets achieve their dimensions and morphology. We include the overlying recrystallized layers in their thickness. The lengths of the stacked bedding sequences determine primary lengths of recrystallized layers.

We use the depths to the beds of Cs3 in Figure $5 \mathrm{a}$ for $z_{\mathrm{b}}$ and our GPS data for $z_{\mathrm{s}}$ along the traverse (and wind) direction, and the $5 \mathrm{~m}$ ICESat DEM starting from the $36 \mathrm{~km}$ distance for our along-ice model. We located $x_{0}$ in Eqn (2) at arrow B in Figure 5a. Each accumulation contour represents 15.4 years of accumulation at the interpolated speed of $32.5 \mathrm{~m} \mathrm{a}^{-1}$ where Cs 3 crosses the traverse at $36 \mathrm{~km}$.

Figure $7 \mathrm{a}$ and $\mathrm{b}$ show Cs3 and our 2-D model along the wind direction, respectively. In Figure $7 \mathrm{~b}$ the initial Gaussian accumulation contour is centered on the windward side, with $\sim 1 \mathrm{~km}$ of accumulation extending onto the crest. Although the model plane is in the windward direction, the actual ice speed is assumed to keep the accumulation stable, and to simplify our transformation to the ice velocity direction. The model approximates the profiled bottom contour of Cs3 and its variation in thickness of $30-48 \mathrm{~m}$, with the greatest thickness at $46 \mathrm{~km}$. The model fails to give the correct depths south of the accumulation source synforms where accumulation appears skewed to the south, whereas the Gaussian function is symmetrical. Given the $40 \times$ vertical exaggeration, Cs3 shows little variation in thickness and almost a linear decrease in elevation.

Figure $7 \mathrm{c}$ and d show our reconstruction and a topographically uncorrected version along the direction of ice flow. In Figure $7 \mathrm{c}$ the stretching and incorporation of the surface topography place the initial accumulation along a surprisingly down-ice-dipping (but not necessarily leeward) slope just northeast of the western end of accumulation feature $\underline{c}$. We expect accumulation there because of the dark tone of the RADARSAT image. In fact, elevation rises across the tip of feature $\underline{c}$ and to the southwest. The additional dark RADARSAT areas along the ice flow arrow in Figure 6a show that this situation is more complicated than our simplification.

The initial accumulation contour has an inverted Gaussian shape that spans $5 \mathrm{~km}(D=0.5)$ in Figure $7 \mathrm{~b}$, and $8 \mathrm{~km}$ (after stretching, which required $D=0.25$ ) in Figure 7c. This decrease in $D$ required a corresponding decrease in $A$. In Figure $7 \mathrm{c}$ and $\mathrm{d}$ the peak values of the accumulation rates, $A$, vary from 0.28 to $0.43 \mathrm{~m} \mathrm{a}^{-1}$ for firn of average density $765 \mathrm{~kg} \mathrm{~m}^{-3}$, from the start of the bed (i.e. the rate at present) to its deepest part. These values equal $0.21-0.33 \mathrm{~m}$ w.e. $\mathrm{a}^{-1}$, significantly exceeding measured regional rates, as do their averages over the slopes $\left(0.11-0.16\right.$ m w.e. $\left.^{-1}\right)$. Varying the 
bed length by $\pm 1 \mathrm{~km}$ varies the required peak accumulation rate only by $\pm 0.03 \mathrm{~m}$ w.e. $\mathrm{a}^{-1}$, so these rates are fairly stable with regard to error in estimating bed length.

Although the full Gaussian distributions along wind and ice-flow directions span 5 and $8 \mathrm{~km}$, respectively, after superposition the sloping beds correctly span about 3.5$5 \mathrm{~km}$, merge along the borders of the sequences, and simulate the sigmoidal shape of the actual beds after several contours. Consequently, the maximum bed separations are not near the bottom of Cs3 where the contours appear to peak, but along the bed slope. The maximum separation of the contours lies between $0.5 A$ and $A$. A vertical cross section through the thicker section intersects up to ten contours, or $\sim 140$ years of accumulation and $47 \mathrm{~m}$ of thickness including the upper recrystallized layer.

The thickness scales linearly with accumulation rate so that a peak value of $0.69 \mathrm{~m}$ w.e. $\mathrm{a}^{-1}$ would achieve the $\sim 100 \mathrm{~m}$ thickness of Cs1 moving at the same ice speed and given the same value of $D=0.5$. However, the bed lengths of Cs1 in this windward side view of Figure $4 \mathrm{a}$ are $8-10 \mathrm{~km}$. Therefore they are likely closer to $13-16 \mathrm{~km}$ long along ice flow, which simply results from ice flow crossing feature $\underline{b}$ (Fig. 6a) so obliquely to its strike. In this along-ice case, the model exponential factor decreases to $D=0.05$, and the peak and average accumulation rates along the slope are then 0.31 and $0.15 \mathrm{~m}$ w.e. $\mathrm{a}^{-1}$, virtually the same as for the thinner Cs3.

\section{DISCUSSION}

\subsection{Spatial stability of windward slopes and bedding alignment}

Despite our traverse not being well aligned with the ice flow direction, the windward slopes for Cs1, 3 and 5 are all situated over 10-13 km long subglacial depressions and precede the rise in subglacial elevation by a few kilometers. In all cases, the subglacial depressions drop between 170 and $400 \mathrm{~m}$. In none of the profiles do we find evidence of significant present-day accumulation upwind of the surface expression of these ice-bed topographic lows. The lows create a local backslope, which in turn creates the conditions for local accumulation. Accumulation, driven by the antidunal progradation into the wind, is therefore isolated both laterally and along-ice-flow by the local backslope.

Spatial stability of surface slopes was predicted by Budd and Carter (1971), whose criteria were (1) that the slopes be over ice-bed depressions with characteristic lengths $\sim 3.3$ times the ice thickness, (2) that the surface rise precede the subglacial rise by about one-quarter of this length, and (3) that there be basal slip. Our ice thickness of $2.6-3.2 \mathrm{~km}$, the misalignment between surface and subglacial slopes and our ice speeds of $30-87 \mathrm{~m} \mathrm{a}^{-1}$ meet these requirements. Gudmundsson (2003), Schoof (2003) and Raymond and Gudmundsson (2005) also found that surface topography responds to subglacial features with similar ratios of ice thickness to length, and that predictable phase differences occur between surface and subglacial topography. However, more directly applying their findings would require 3-D knowledge of the bed and surface topography, and estimates of stress parameters which we do not have. Given the likely large area of these depressions, it seems reasonable that these predictions hold even when ice flow is oblique to profile direction, as happens here. We discuss stratigraphic evidence for basal slip in Part II.

\subsection{Accumulation rates}

Although our highest modeled peak accumulation rate of 0.33 m w.e. $\mathrm{a}^{-1}$ is greater than expected for East Antarctica, Figure $7 d$ shows that this rate explains the thickness of only one section. The means for all sections are $0.26 \mathrm{~m}$ w.e. $\mathrm{a}^{-1}$ peak and $0.13 \mathrm{~m}$ w.e. $\mathrm{a}^{-1}$ average along the slope. However, the lowest average rate of $0.11 \mathrm{~m}$ w.e. $\mathrm{a}^{-1}$ is still significantly higher than the maximum megadune measurement of $0.07 \mathrm{mw}$.e. $\mathrm{a}^{-1}$ (Frezzotti and others, 2002). It is also significantly higher than the rates of Courville and others (2007) and T. Scambos (personal communication, 2011), 0.03-0.04 mw.e. $\mathrm{a}^{-1}$, which were obtained on megadune windward slope crests where their GPR profiles show strongest accumulation. Our profiles also show accumulation on crests, but that maximum values are likely near the midpoints of our relatively larger windward slopes.

Given that glaze might cover $60-72 \%$ of the areas between dune fields and given regional accumulation rates of $0.04-0.05 \mathrm{mw} . \mathrm{e} . \mathrm{a}^{-1}$, then a slope average of at least $0.11 \mathrm{~m}$ w.e. $\mathrm{a}^{-1}$ over the remaining $28-40 \%$ might suggest that the intensified accumulation is caused by the mass blown off the leeward slopes, and that the intensified rates compensate the glaze to produce the regional average. However, the intensified rates we calculate should be uncommon because of the high ice speeds we encountered and the associated stability requirements. Most large, dark RADARSAT features within Byrd catchment (Fig. 1) are upflow where speeds are undoubtedly much lower, and we have only limited evidence that they are spatially stable (Part II). When we apply our model to a particularly thick one in Part II, based on englacial evidence, we find an average slope rate of $\sim 0.09 \mathrm{~m} \mathrm{a}^{-1}$. When we apply our model to the megadune cosets of Scambos and others (2004), we find the correct coset thicknesses of $7-12 \mathrm{~m}$ when we use their measured 0.03-0.04 mw.e. $\mathrm{a}^{-1}$ accumulation rates and $4 \mathrm{ma}^{-1}$ ice speed. Therefore, it appears that neither the measured megadune rates nor those predicted by our model for lower ice speeds would provide rates that would compensate the glazed areas unless regional rates are near $0.02 \mathrm{~m}$ w.e. $\mathrm{a}^{-1}$, which balances the flux through Byrd Glacier (Stearns, 2007).

\subsection{Continued growth of recrystallization}

The modified layers in Figures 4 and 5 thicken and merge, thereby covering major portions of the firn. There are at least two possible ways this recrystallization growth is promoted. The first is under virtually isothermal conditions, as demonstrated experimentally (Kaempfer and Schneebeli, 2007) and long considered to exist throughout firn below a few meters depth (Gow, 1969; Alley, 1988; Gow and others, 2004; Spaulding and others, 2010). A second and more likely way is by wind-pumped vapor transported from the surface through thermal cracks, effective to at least $23 \mathrm{~m}$ depth (Severinghaus and others, 2010) and long since known to be associated with glazed surfaces (Giovinetto, 1963). Along our traverse, our field party encountered dense networks of such cracks $0.2 \mathrm{~m}$ or more wide, meters apart, and measured a depth of at least $33 \mathrm{~m}$ in one that was at least a few meters wide at the surface. We suggest that the layers themselves provide pathways to greater depths because all ultimately connect to the surface. The thickening with depth suggests that, as they descend, they retain some permeability. Such surface connection may preclude the case for constant and long-term isothermal conditions in glazed areas. An additional example is described in the Appendix. 


\subsection{Coset age}

We consider the likely age represented by a coset of prograded snow, and similarly, that of the recrystallized firn layer on its leeward surface because it was once part of the bedding. We use the model in Figure 7, the interpolated ice flow speed, and our requirement of an amplified accumulation rate that maintains the windward face position above the ice-bed-induced low in topography. The length of the modeled coset in Figure 7c or $d$ is $40 \mathrm{~km}$, beginning at the center of the initial deposition at the $40 \mathrm{~km}$ location. At the interpolated ice flow speed of $32.5 \mathrm{~m} \mathrm{a}^{-1}$ this length represents 1231 years. In the model, however, it is the 73rd horizon that intersects the surface at this end, which represents 1109 years. This latter age is less because of the width of the accumulation distribution. Deeper contours at this end would be accordingly older.

\section{CONCLUSIONS}

An unconformity begins with the accumulation hiatus of glazed leeward slopes, which becomes conspicuous in a radar profile after the accumulation below this slope recrystallizes and loses density stratification. After burial the unconformity then becomes the isochronal interface between the upper border of the modified layer and the prograded bedding sequence above it. An entire coset, consisting of a bedding sequence and modified layer, may be almost $100 \mathrm{~m}$ thick and $40 \mathrm{~km}$ long. Continued recrystallization after burial produces unstratified layers up to tens of meters thick and may erase the original density contrast that defined an isochronal and unconformable surface. The faded horizon intensity north of $30 \mathrm{~km}$ in segment T1 implies that the recrystallized layers could exceed $90 \mathrm{~m}$ thickness. Given our modeled age of $>1000$ years for coset 3 , the thickest of these layers has likely grown for a similar time. Although isothermal recrystallization is possible, it seems likely that the growth may be caused primarily by vapor transported through deep surface cracks and then propagated through the layers themselves. A program to drill into the modified firn would help explain this apparent postburial, low-thermal-gradient growth

Our windward slope accumulation areas appear spatially stable because the four we encountered beneath features a$\underline{\mathrm{d}}$ lie over subglacial depressions. The stability implies no prograded accumulation beyond the slopes into, or obliquely to, the wind direction. Although our argument for bedrock control is weakened by poor alignment of our profiles with ice flow direction and by lack of data to constrain the 3-D extent of the depressions, our subglacial examples span the theoretically required distance of three times the ice depth or more for surface topography to respond, and show surface slopes lagging the subglacial slopes, as expected.

Our model of coset 3 reproduces the dimensions and morphology of our along-wind radar profile. The superposition of closely spaced accumulation contours is critical for our simulation. The change into an along-flow view resulted in longer beds. Our along-flow model appears to have run into difficulties because ICESat data (DiMarzio and others, 2007) place the origin on a down-ice slope, while the origin appears to be at the western tip of accumulation feature $\underline{c}$ (Fig. 3a). Unfortunately, we have no profiles to show whether this source area is now glazed, and there may be sub-resolution issues with the DEM we used. Consequently, this example suggests that windward slopes are a general, but not a certain, indication of present accumulation.

Peak accumulation rates of $0.21-0.33 \mathrm{~m}$ w.e. $\mathrm{a}^{-1}$ coupled with high ice speed are required to produce our coset thicknesses. Our high ice speeds in excess of $30 \mathrm{~m} \mathrm{a}^{-1}$ appear exceptional because the traverse was near streaming flow. In terms of slope averages, the accumulation rates are half these values, but still significantly above estimated regional rates and those measured on megadune crests. It is unlikely that accumulation rates upon all large, dark RADARSAT features are similarly high, mainly because most of them within Byrd catchment are up-flow where speeds are undoubtedly much less, and yet are possibly spatially stable (Part II). Consequently, despite the intensification being likely caused by snow blown off the leeward slopes, it appears unlikely that intensified accumulation compensates for the widespread glaze to produce estimated regional accumulation rates of $0.04-0.05 \mathrm{~m} \mathrm{a}^{-1}$. However, the accumulation rates could be sufficient to maintain the elevation of this part of the plateau by advective spreading of the very slight aggradation associated with windward-side accumulation. Although the unconformable firn horizons represent discontinuous accumulation and a challenge to assessing present, and historical, regional accumulation rates, potentially suitable ice-core sites on large and isolated windward slopes may be identified with RADARSAT imagery and verified with GPR to select those slopes without recrystallized layers.

The constant appearance of unconformable and irregular firn strata for $650 \mathrm{~km}$, the traverse orientation and location, and the paucity of visible megadunes nearby, all imply that unconformable coset and recrystallized strata are ubiquitous up-flow of our traverse and between the megadune fields. However, the $90 \mathrm{~m}$ profiling depth provides an estimated upice sample space of no more than $\sim 54 \mathrm{~km}$ from our traverse, given an average ice speed of $\sim 30 \mathrm{ma}^{-1}$ and a regional average accumulation rate of $0.05 \mathrm{~m} \mathrm{a}^{-1}$. The extensive unconformable englacial stratigraphy we concurrently recorded (Part II) reveals a far greater up-ice and historical extent of this stratigraphy.

\section{ACKNOWLEDGEMENTS}

This research was supported by US National Science Foundation (NSF) Office of Polar Programs (OPP) grants 188643 (Arcone), 188987 (Jacobel) and 188765 (Hamilton). We thank Brian Welch and Daniel Breton for GPR recording and GPS processing; Brian Tracey, Seth Campbell, Kristin Schild and Monica Palmer for image processing; Ted Scambos, Jeffrey Severinghaus and Christopher Schuman for helpful comments during a conference in March 2008; and Paul Mayewski for his organization and leadership of the ITASE projects. We also thank Ted Scambos for his careful critique of the manuscript and helpful suggestions. Permission to published was granted by Director, Cold Regions Research and Engineering Laboratory.

\section{REFERENCES}

Albert M, Shuman C, Courville Z, Bauer R, Fahnestock M and Scambos T (2004) Extreme firn metamorphism: impact of decades of vapor transport on near-surface firn at a lowaccumulation glazed site on the East Antarctic plateau. Ann. Glaciol., 39, 73-78 (doi: 10.3189/172756404781814041)

Alley RB (1988) Concerning the deposition and diagenesis of strata in polar firn. J. Glaciol., 34(118), 283-290 
Arcone SA and Jacobel RW (2008) Megapackets and megapseudosynclines profiled with GPR east of the megadunes region, East Antarctica. Eos, 89(53), Fall Meet. Suppl. [Abstr.C31B-0487]

Arcone SA, Spikes VB, Hamilton GS and Mayewski PA (2004) Stratigraphic continuity in $400 \mathrm{MHz}$ short-pulse radar profiles of firn in West Antarctica. Ann. Glaciol., 39, 195-200 (doi: 10.3189/172756404781813925)

Arcone SA, Spikes VB and Hamilton GS (2005a) Phase structure of radar stratigraphic horizons within Antarctic firn. Ann. Glaciol., 41, 10-16 (doi: 10.3189/172756405781813267)

Arcone SA, Spikes VB and Hamilton GS (2005b) Stratigraphic variation in polar firn caused by differential accumulation and ice flow: interpretation of a $400 \mathrm{MHz}$ short-pulse radar profile from West Antarctica. J. Glaciol., 51(174), 407-422 (doi: 10.3189/172756505781829151)

Arcone SA, Jacobel RW and Hamilton GS (2012) Unconformable stratigraphy in East Antarctica: Part II. Englacial cosets and recrystallized layers. J. Glaciol., 58(208), 253-264

Arthern RJ, Winebrenner DP and Vaughan DG (2006) Antarctic snow accumulation mapped using polarization of $4.3 \mathrm{~cm}$ wavelength microwave emission. J. Geophys. Res., 111(D6), D06107 (doi: 10.1029/2004JD005667)

Bamber JL, Gomez-Dans JL and Griggs JA (2009) A new $1 \mathrm{~km}$ digital elevation model of the Antarctic derived from combined satellite radar and laser data - Part 1: data and methods. Cryosphere, 3, 101-111 (doi: 10.5194/tc-3-101-2009)

Bauer R, Scambos T and Haran T (2004) GPS and GPR profiles of snow megadunes in East Antarctica. Eos, 85(47), Fall Meet. Suppl. [Abstr. C43A-0220]

Black HP and Budd W (1964) Accumulation in the region of Wilkes, Wilkes Land, Antarctica. J. Glaciol., 5(37), 3-15

Bohlander J and Scambos T (2005) Outlines of Antarctic megadunes regions. National Snow and Ice Data Center, Boulder, CO. Digital media: http://geopole.org/map/ms/w0fzgt/491381

Budd WF and Carter DB (1971) An analysis of the relation between the surface and bedrock profiles of ice caps. J. Glaciol., 10(59), 197-209

Courville ZR, Albert MR, Fahnestock MA, Cathles LM and Shuman CA (2007) Impacts of an accumulation hiatus on the physical properties of firn at a low-accumulation polar site. J. Geophys. Res., 112(F2), F02030 (doi: 10.1029/2005JF000429)

DiMarzio J, Brenner A, Schutz R, Shuman CA and Zwally HJ (2007) GLAS/ICESat $500 \mathrm{~m}$ laser altimetry digital elevation model of Antarctica. National Snow and Ice Data Center, Boulder, CO. Digital media: http://nsidc.org/data/nsidc-0304.html

Dixon DA (2008) Antarctic mean annual temperature map. National Snow and Ice Data Center, Boulder, CO. Digital media: http://nsidc.org/data/nsidc-0318.html

Fahnestock MA, Scambos TA, Shuman CA, Arthern RJ, Winebrenner DP and Kwok R (2000) Snow megadune fields on the East Antarctic Plateau: extreme atmosphere-ice interaction. Geophys. Res. Lett., 27(22), 3719-3722 (doi: 10.1029/ 1999GL011248)

Fahnestock MA, Shuman CA, Albert M and Scambos T (2004) Satellite, observational, meteorological and thermal records from two sites in the Antarctic megadunes: stability of atmospheric forcing, thermal cracking, and the seasonal evolution of the thermal profile. Eos, 85(47), F455 [Abstr. C31C-03]

Frezzotti M, Gandolfi S and Urbini S (2002) Snow megadunes in Antarctica: sedimentary structure and genesis. J. Geophys. Res. 107(D18), 4344 (doi: 10.1029/2001JD000673)

Frezzotti M and 13 others (2005) Spatial and temporal variability of snow accumulation in East Antarctica from traverse data. J. Glaciol., 51(172), 113-124 (doi: 10.3189/ 172756505781829502)

Fujii Y and Kusunoki K (1982) The role of sublimation and condensation in the formation of ice sheet surface at Mizuho Station, Antarctica. J. Geophys. Res., 87(C6), 4293-4300 (doi: 10.1029/JC087iC06p04293)
Giovinetto MB (1963) Glaciological studies on the McMurdoSouth Pole traverse, 1960-1961. Inst. Polar Stud. Rep. 7.

Gow AJ (1969) On the rates of growth of grains and crystals in South Polar firn. J. Glaciol., 8(53), 241-252

Gow AJ, Meese D and Bialas R (2004) Accumulation variability, density profiles and crystal growth trends in ITASE firn and ice cores from West Antarctica. Ann. Glaciol., 39, 101-109 (doi: 10.3189/172756404781814690)

Gudmundsson GH (2003) Transmission of basal variability to a glacier surface. J. Geophys. Res., 108(B5), 2253 (doi: 10.1029/ 2002JB0022107)

Jacobel RW and 6 others (2008) Accumulation patterns and basal conditions from radar observations along the US-ITASE traverse in East Antarctica. Eos, 89(53), Fall Meet. Suppl. [Abstr. C31B0486]

Jezek KC (2003) Observing the Antarctic ice sheet using the RADARSAT-1 synthetic aperture radar. Polar Geogr., 27(3), 197-209 (doi: 10.1080/789610167)

Kaempfer TU and Schneebeli M (2007) Observation of isothermal metamorphism of new snow and interpretation as a sintering process. J. Geophys. Res., 112(D24), D24101 (doi: 10.1029/ 2007JD009047)

Kovacs A, Gow AJ and Morey RM (1996) The in-situ dielectric constant of polar firn revisited. Cold Reg. Sci. Technol., 23(3), 245-256 (doi: 10.1016/0165-232X(94)00016-Q)

Langley K and 6 others (2007) Use of C-band ground penetrating radar to determine backscatter sources within glaciers. IEEE Trans. Geosci. Remote Sens., 45(5), 1236-1246 (doi: 10.1109/ TGRS.2007.892600)

Langley K, Lacroix P, Hamran S-E and Brandt O (2009) Sources of backscatter at $5.3 \mathrm{GHz}$ from a superimposed ice and firn area revealed by multi-frequency GPR and cores. J. Glaciol., 55(190), 373-383 (doi: 10.3189/002214309788608660)

Liu H, Jezek KC and Li B (1999) Development of an Antarctic digital elevation model by integrating cartographic and remotely sensed data: a geographic information system based approach. J. Geophys. Res., 104(B10), 23 199-23 213 (doi: 10.1029/ 1999JB900224)

Liu H, Jezek K, Li B and Zhao Z (2001) Radarsat Antarctic mapping project digital elevation model version 2. National Snow and Ice Data Center, Boulder, CO. Digital media: http://nsidc.org/data/ nsidc-0082.html

Mayewski PA (2003) Antarctic oversnow traverse-based Southern Hemisphere climate reconstruction. EOS, 84(22), 205-210

Miall AD (1996) The geology of fluvial deposits: sedimentary facies, basin analysis, and petroleum geology. Springer-Verlag, Berlin

Parish TR (1988) Surface winds over the Antarctic continent: a review. Rev. Geophys., 26(1), 169-180

Parish TR and Bromwich DH (1987) The surface windfield over the Antarctic ice sheets. Nature, 328(6125), 51-54

Prothero DR and Schwab F (1996) Sedimentary geology: an introduction to sedimentary rocks and stratigraphy. WH Freeman, New York

Raymond MJ and Gudmundsson GH (2005) On the relationship between surface and basal properties on glaciers, ice sheets, and ice streams. J. Geophys. Res., 110(B8), B08411 (doi: 10.1029/ 2005JB003681)

Scambos T, Fahnestock M, Shuman C and Bauer R (2004) Antarctic megadunes: characteristics and formation. EOS, 85(47), F455 [Abstr. C31C-04]

Schoof C (2003) The effect of basal topography on ice sheet dynamics. Contin. Mech. Thermodyn., 15(3), 295-307 (doi: 10.1007/s00161-003-0119-3)

Severinghaus JP and 12 others (2010) Deep air convection in the firn at a zero-accumulation site, central Antarctica. Earth Planet. Sci. Lett., 293(3-4), 359-367 (doi: 10.1016/j.epsl.2010.03.003)

Siegert MJ, Hindmarsh RCA and Hamilton GS (2003) Evidence for a large surface ablation zone in central East Antarctica during the last Ice Age. Quat. Res., 59(1), 114-121 (doi: 10.1016/S00335894(02)00014-5) 


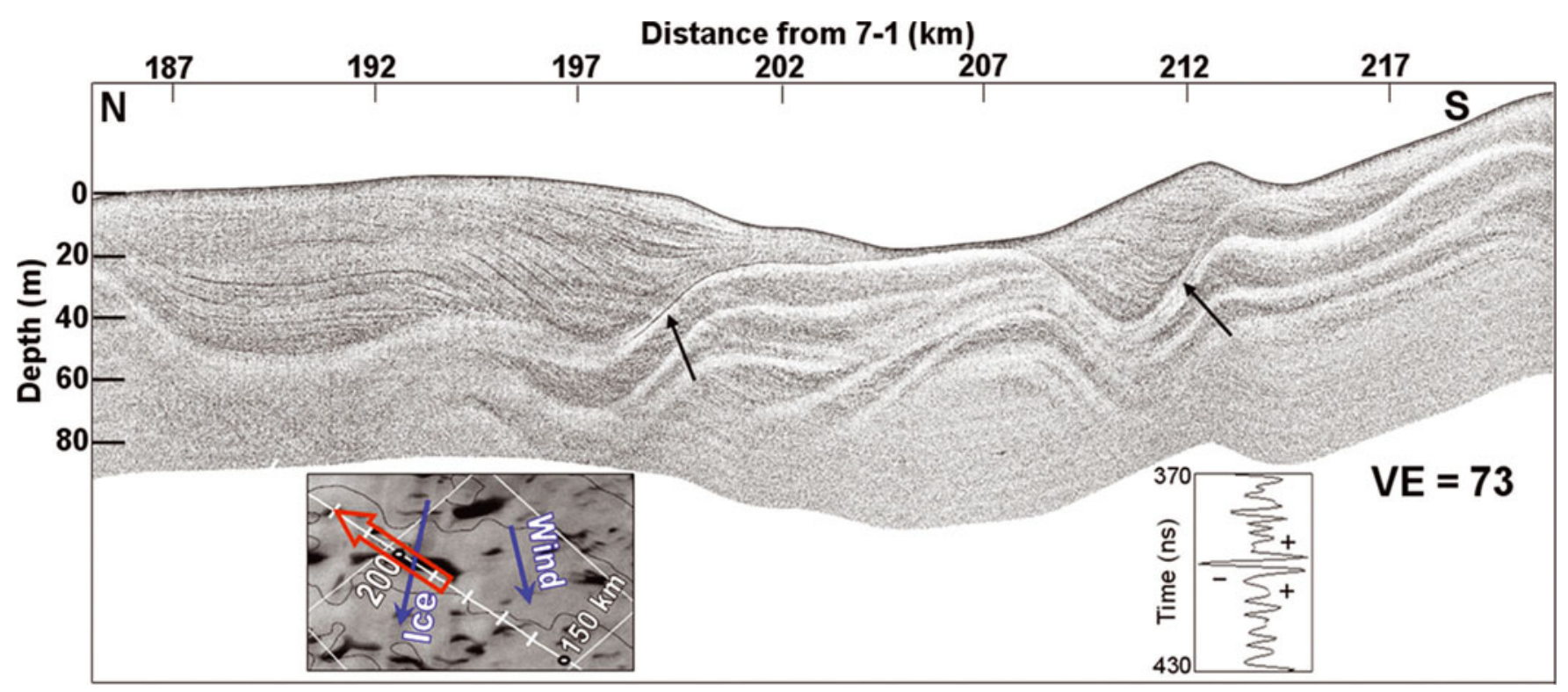

Fig. 8. Profile of segment T2 showing modified layers that merge into zones. Flow is mainly into the page. The black arrows indicate thin glaze horizons; the horizon at left shows unstratified growth above and below it. The left inset shows T2 (red arrow) superimposed on the RADARSAT image of the region. The right inset shows the waveform of the glaze response at $198.9 \mathrm{~km}$ distance. The +-+ symbols in this inset refer to the sign of the signal amplitude.

Spaulding NE, Meese DA, Baker I, Mayewski PA and Hamilton GS (2010) A new technique for firn grain-size measurement using SEM image analysis. J. Glaciol., 56(195), 12-19 (doi: 10.3189/ 002214310791190893)

Spikes VB, Hamilton GS, Arcone SA, Kaspari S and Mayewski P (2004) Variability in accumulation rates from GPR profiling on the West Antarctic plateau. Ann. Glaciol., 39, 238-244 (doi: 10.3189/172756404781814393)

Stearns LA (2007) Outlet glacier dynamics in East Greenland and East Antarctica. (PhD thesis, University of Maine)

Swithinbank C (1988) Antarctica. In Williams RS, Jr and Ferrigno JG eds. Satellite image atlas of glaciers of the world. United States Geological Survey, Denver, CO, B1-B138 (USGS Professional Paper 1386-B)

Van de Berg WJ, Van den Broeke MR, Reijmer $\mathrm{CH}$ and Van Meijgaard E (2006) Reassessment of the Antarctic surface mass balance using calibrated output of a regional atmospheric climate model. J. Geophys. Res., 111(D11), D11104 (doi: 10.1029/2005JD006495)

Vaughan DG, Bamber JL, Giovinetto MB, Russell J and Cooper APR (1999) Reassessment of net surface mass balance in Antarctica. J. Climate, 12(4), 933-946 (doi: 10.1175/1520-0442 (1999)012<0933:RONSMB $>2.0 . C O ; 2)$

Welch BC, Jacobel RW and Arcone SA (2009) First results from radar profiles collected along the US-ITASE traverse from Taylor Dome to South Pole (2006-2008). Ann. Glaciol., 50(51), 35-41 (doi: 10.3189/172756409789097496)

Whillans IM (1975) Effect of inversion winds on topographic detail and mass balance on inland ice sheets. J. Glaciol., 14(70), 85-90

\section{APPENDIX: RECRYSTALLIZED CONNECTIONS AT DEPTH}

Figure 8 provides another example of recrystallized layers that permeate firn, with all eventually connected to the surface. We recorded this profile along segment T2, located $185-221 \mathrm{~km}$ from site $7-1$. The modeled wind direction is $\sim 45^{\circ}$ off the traverse direction. Local, megadune-type features are $10 \mathrm{~km}$ to the west, with strikes generally orthogonal to the modeled wind. The interpolated ice flow is nearly orthogonal to T2. Therefore, this profile is an oblique cross section of cosets that formed up-flow of the traverse. The stratification to $40 \mathrm{~m}$ depth and from 185 to $202 \mathrm{~km}$ is associated with a dark RADARSAT accumulation area. The profile clearly shows many modified layers that eventually merge into zones, and at various depths. In the central section, nearly the entire firn column has recrystallized. Surface connection is near $207 \mathrm{~km}$ distance and likely further up-flow. An orthogonal profile along the ice flow direction would likely show far more extended surface contact, as in Figures 4 and 5.

In Figure 8 the thin dark horizons are responses to former glaze because they can be followed to the surface. The modified layers that thicken above and below the one near km 199 show that recrystallization grows downward and upward, and so modified or eradicated the original unconformable horizon, as defined by a density contrast. The continued growth suggests the firn is permeable to $>40 \mathrm{~m}$ depth. The consistency of the +-+ phase polarity sequence and simplicity of the waveform along the horizon show that this layer is thinner than an in situ wavelength $(0.9 \mathrm{~m})$ and denser than the surrounding firn (Arcone and others, 2005a). This is consistent with observations by Gow (1969), Fujii and Kusunoki (1982) and Frezzotti and others (2002). Fujii and Kusunoki (1982) measured a density of $690 \mathrm{~kg} \mathrm{~m}^{-3}$ for surface glaze $4 \mathrm{~mm}$ thick. Although glaze layers can be as thin as $2 \mathrm{~mm}$, which is much less than the in situ wavelength, such thicknesses still provide appreciable reflectivities of -45 to $-55 \mathrm{~dB}$ (Arcone and others, 2004). With burial, the glaze horizon disappears and so the density may have increased to almost that of impermeable ice by $50 \mathrm{~m}$ depth $\left(820 \mathrm{~kg} \mathrm{~m}^{-3}\right)$ and completely recrystallized. 